\title{
TWO DISTINCT COMPONENTS OF TUBULIN TRANSPORT IN SENSORY AXONS OF THE RAT RECOGNISED BY DIMETHYL SULFOXIDE TREATMENT
}

\section{TOMOKO TASHIRO and YOSHIAKI KOMIYA}

Department of Biochemistry, Institute of Brain Research, Tokyo University Faculty of Medicine, Hongo, Bunkyoku, Tokyo 113, Japan

\begin{abstract}
Two components of tubulin transport migrating at different rates were recognised one week after injection of $\mathrm{L}-\left[{ }^{35} \mathrm{~S}\right]$ methionine into the lumbar fourth $\left(\mathrm{L}_{4}\right)$ dorsal root ganglion of the rat when $50 \%$ dimethyl sulfoxide (DMSO) had been injected into the ganglion immediately before the isotope. The effect of DMSO was to specifically enhance the transport velocity of a portion of tubulin, separating it into a faster wave ahead of the bulk of slowly transported proteins. Electrophoretic analysis revealed that the two waves of tubulin differed in subunit composition. The DMSO-induced faster wave lacked the two prominent polypeptides present in the original slow transport wave. This change in tubulin composition along the nerve observed after DMSO treatment does not seem to represent a pathological process. It seems rather to be an acceleration of the physiological process, because even in the untreated nerve, tubulin is separated after a longer time interval into two populations, one migrating with the neurofilament triplet and the other migrating faster independently of the triplet.
\end{abstract}

Dimethyl sulfoxide (DMSO), frequently used as a solvent for water-insoluble drugs, is known to have effects on the cytoskeletal proteins. When included in culture medium, it causes the disappearance of cortical microfilaments and the formation of actin bundles in the nucleus, leading to cessation of cytokinesis and cell division (4-6, 19). DMSO also induces the in vitro assembly of tubulin in the absence of associated proteins and stabilises the polymerised microtubules $(8$, 18). When applied to the in vitro axonal transport system where the whole length of nerve was exposed to DMSO, it inhibits fast transport reversibly $(3,7)$. Its effects on the slow transport, however, have not been tested.

We report here the effect of DMSO on the slow axonal transport of cytoskeletal proteins when injected into the cell body region $(10,12)$. Under these conditions, a second, faster wave of tubulin appeared in addition to the original one. Differences were found between the polypeptide composition of tubulin in this faster peak and that of tubulin migrating at the original speed. Similar splitting of tubulin transport into two components occurs in the non-treated nerve as well, but after a longer time interval.

\section{MATERIALS AND METHODS}

Male albino rats of the Wistar strain, 7 weeks old, were used throughout the experiment. L[ ${ }^{35}$ S]Methionine (New England Nuclear, Boston, U.S.A.) concentrated by lyophilisation (30-40 $\mu \mathrm{Ci}$ in $0.25 \mu \mathrm{l}$ ) was injected into the $\mathrm{L}_{4}$ dorsal root ganglion as described previously (11). In some cases, $0.22 \mu \mathrm{l}$ of $50 \%$ DMSO was injected into the ganglion at appropriate time intervals prior to or after the isotope injection. One or two weeks postlabelling, the animals were killed by decapitation and the sciatic nerve, $\mathbf{L}_{4}$ 


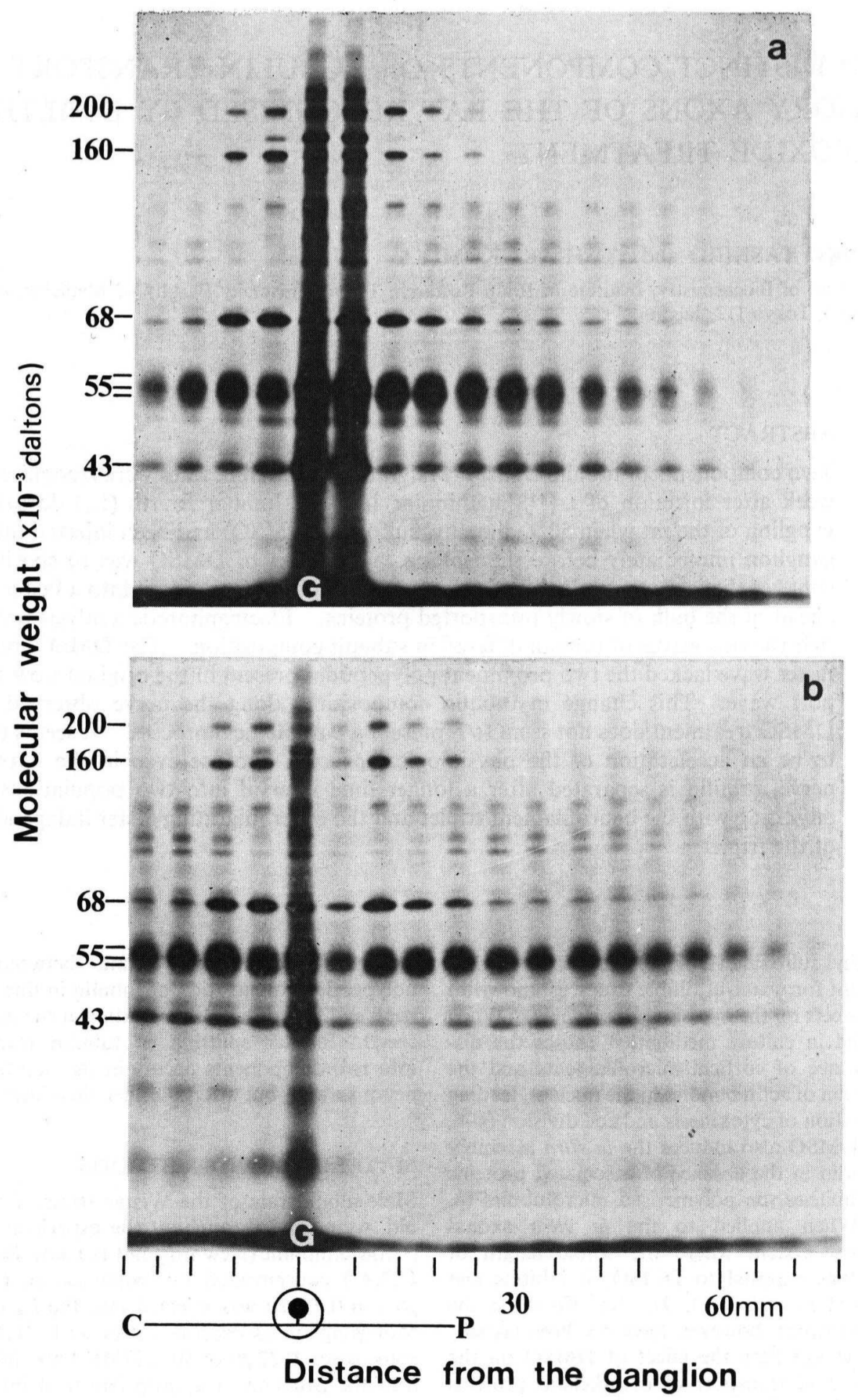

Fig. 1 


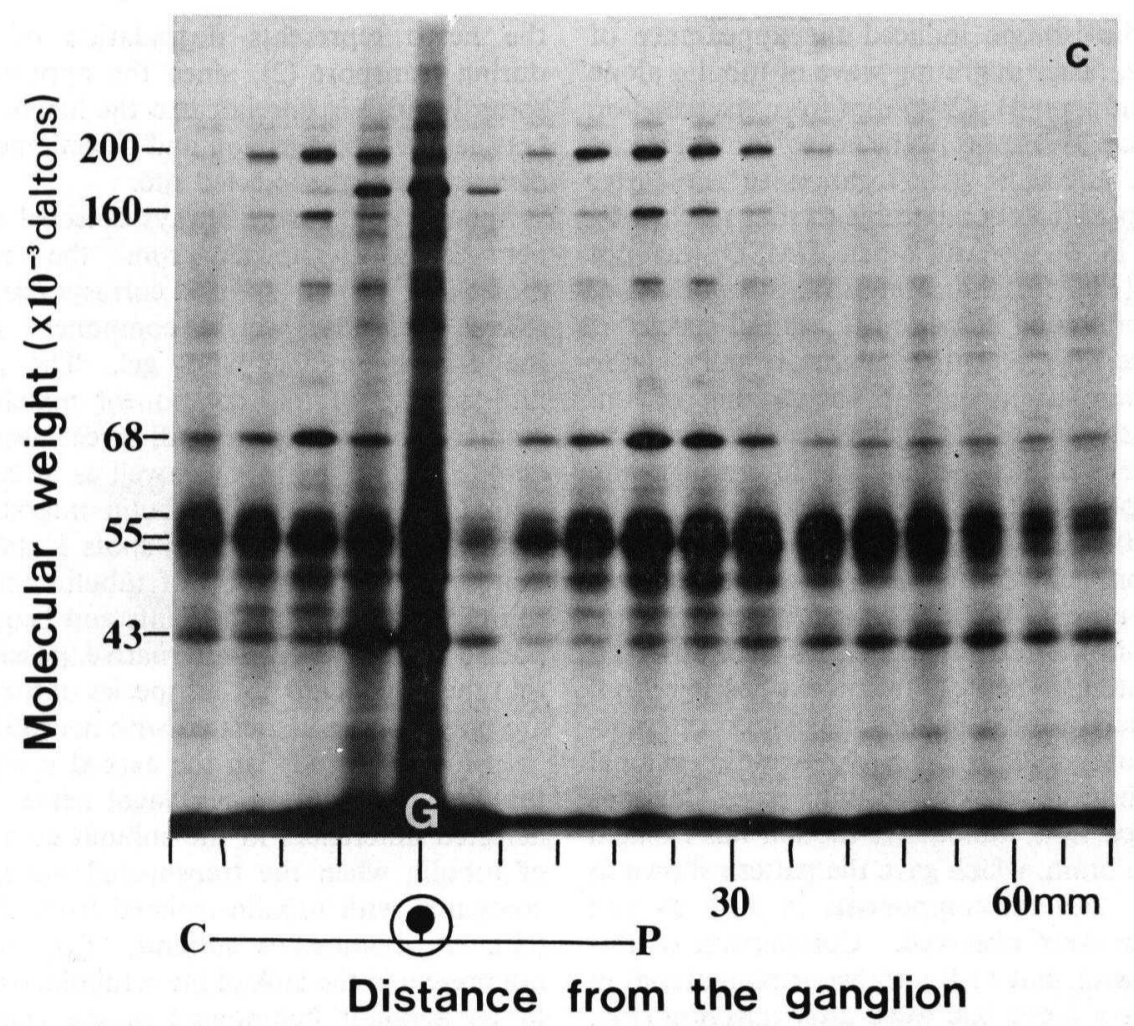

Fig. 1 Analyses of slowly migrating proteins in DMSO-treated and in control nerves. $\mathrm{L}-\left[{ }^{35} \mathrm{~S}\right] \mathrm{Methionine}$ was injected into the $\mathrm{L}_{4}$ dorsal root ganglion either by itself or immediately following $50 \%$ DMSO. One or two weeks after isotope injection, labelled proteins in $6 \mathrm{~mm}$ consecutive segments of the dorsal root and the sciatic nerve were separated by SDS gel electrophoresis and detected by fluorography. C, Central branch (dorsal root); $\mathrm{P}$, Peripheral branch (sciatic nerve). a: Control, one week postlabelling. b: DMSOtreated, one week postlabelling. c: Control, two weeks postlabelling

ganglion, and $\mathrm{L}_{4}$ dorsal root were dissected out, frozen on a plastic plate, and cut into consecutive $3 \mathrm{~mm}$ segments.

For one-dimensional electrophoresis, each nerve segment was homogenised in $200 \mu \mathrm{l}$ of sodium dodecylsulfate (SDS) sample buffer containing $2 \%$ SDS, $80 \mathrm{mM}$ Tris(hydroxymethyl)aminomethane (pH 6.8), $5 \mathrm{mM} \beta$-mercaptoethanol, and $10 \%$ glycerol. After heating at $100^{\circ} \mathrm{C}$ for $3 \mathrm{~min}$, aliquots of the homogenate were subjected to SDS gel electrophoresis (13) on $10 \%$ acrylamide gels and processed for fluorography as described by Bonner and Laskey (1).

For two-dimensional electrophoresis (17), segments were frozen in liquid nitrogen, crushed to fine powder with an air hammer, and homogenised in lysis buffer containing $2 \%$ Nonidet P40, 9.5 M urea, 2\% Ampholines (LKB, Sweden), and $0.5 \% \beta$-mercaptoethanol.
Radioactive tubulin was prepared from labelled rat brain by two cycles of polymerisation and depolymerisation (20) $3 \mathrm{~h}$ after injection of $\mathrm{L}-\left[{ }^{35} \mathrm{~S}\right] \mathrm{methionine}$ into the lateral ventricle, as described (22).

\section{RESULTS AND DISCUSSION}

Electrophoretic analysis of labelled proteins in DMSO-treated and in control nerves one week after radioisotope injection are shown in Fig. 1, $a$ and $b$. The slow wave of axonal transport consists mainly of cytoskeletal proteins, the neurofilament triplet $(200 \mathrm{kDa}, 160 \mathrm{kDa}$ and $68 \mathrm{kDa}$ in molecular weight), tubulin $(\sim 55 \mathrm{kDa})$, and actin $(43 \mathrm{kDa})$, as marked in the figure $(9,14$, 16). In the control nerve, the peak of neurofilament radioactivity was located $12 \mathrm{~mm}$ from the ganglion, and that of tubulin was at $18-24 \mathrm{~mm}$ (Fig. 1a). Injection of $50 \%$ DMSO immediately 
before the isotope induced the appearance of a second, faster migrating wave of tubulin alone which had its peak $42-45 \mathrm{~mm}$ from the ganglion (Fig. 1b). Transport of the neurofilament triplet was not affected. The location of the faster tubulin peak was comparable to that reached by tubulin in two weeks when DMSO was not applied (Fig. 1c), indicating that this portion of tubulin migrated at twice the normal speed.

On the SDS gel, three migratory polypeptide bands were discernible in the tubulin region. The relative intensities of these bands seemed to be different in the faster and the slower migrating tubulin peaks in the DMSO-treated nerve. The band with the lowest apparent molecular weight was prominent in the slower wave, but was almost absent in the faster wave. Similar changes in the relative intensities were observed in the untreated nerve at two weeks postinjection.

To analyse the subunit composition of transported tubulin along the nerve, two-dimensional electrophoresis was carried out. As a standard for comparison, radioactive tubulin was isolated from the brain, which gave the pattern shown in Fig. 3b. Several components in both $\alpha$ - and $\beta$-tubulin were observed. Comparison of this pattern with that of the transported material in the control nerve one week after injection (Fig. $2 \mathrm{a}$; corresponds to the length of nerve between 9 and $27 \mathrm{~mm}$ from the ganglion which contains the peak of tubulin radioactivity) showed that in the transported material additional spots were present in the tubulin region. These extra components are marked with arrows in the figure, three in the pI range between that of $\alpha$ - and $\beta$ tubulin (spots 1, 2, and 3 ) and one with the pI more basic than $\alpha$-tubulin (spot 4). A similar length of nerve (between 9 and $24 \mathrm{~mm}$ from the ganglion) from the DMSO-treated animal corresponding to the slower peak of tubulin radioactivity gave a pattern identical to that of the control nerve (Fig. 2c). The faster migrating peak (between 39 and $60 \mathrm{~mm}$ from the ganglion), however, lacked the prominent spots 1 and 2, as seen in Fig. 2d. The difference is even more striking when the two regions of the control nerve were examined two weeks postinjection (Fig. 2, e and f). The length of nerve between 15 and $30 \mathrm{~mm}$ from the ganglion, which corresponds to the peak of neurofilament radioactivity contained spots 1 and 2 as major components, with only a small amount of radioactivity in the $\alpha$ and $\beta$ subunits (Fig. $2 \mathrm{e}$ ). In contrast, further away from the ganglion, between 39 and $60 \mathrm{~mm}$, spots 1 and 2 were absent (Fig. 2f). It is unlikely that this change in subunit composition along the nerve represents degradation of tubulin during transport (2), since the appearance of spots 1 and 2 is unrelated to the length of time between isotope injection and detection or to the distance from the injected site.

Spots 1 and 2 were always detected with the neurofilament triplet. From the apparent molecular weight, spot 2 corresponds to the lowest molecular weight component seen on the one-dimensional SDS gel. The peak of radioactivity of this component matched well with that of the triplet in all three cases shown here (Fig. 1, a, b and c) as well as at later time points, while $\alpha$ - and $\beta$-tubulin migrated at a distinctly faster rate. Thus spots 1 and 2 may represent one population of tubulin specialised to interact with neurofilaments and being transported together. An alternative possibility is that these spots are not subspecies of tubulin but are polypeptides associated with neurofilaments.

In a recent study on the axonal transport of tubulin in the guinea pig vagal nerve, we also detected differences in the subunit composition of tubulin when the transported material was compared with tubulin isolated from the brain (22). A modified $\alpha$ subunit, ' $T_{A x}$ ', which is not present in the bulk of brain tubulin was found to be a major component in the transported tubulin. From the electrophoretic mobility, $\mathrm{T}_{\mathrm{AX}}$ seems to correspond to spot 3 in this report. Polypeptides corresponding to spots 1 and 2, however, were not present in transported tubulin in the vagal nerve. This is reasonable if we assume that these two polypeptides, subspecies of tubulin or not, are associated with neurofila-

Fig. 2 Electrophoretic comparison of transported tubulin in different parts of the nerve either with or without DMSO treatment. Labelled tubulin isolated from rat brain $3 \mathrm{~h}$ after injection of $\mathrm{L}-\left[{ }^{35} \mathrm{~S}\right]$ methionine into the lateral ventricle was included as a standard (b). a: Labelled proteins in the control nerve between 9 and $27 \mathrm{~mm}$ from the ganglion, one week after isotope injection. c: Labelled proteins in the DMSO-treated nerve between 9 and $24 \mathrm{~mm}$ from the ganglion, one week after isotope injection. d: Labelled proteins in the DMSO-treated nerve as in c, except that the length of nerve between 39 to $60 \mathrm{~mm}$ from the ganglion was taken (the faster-migrating peak). e: Labelled proteins in the control nerve between 15 and $30 \mathrm{~mm}$ from the ganglion, two weeks after isotope injection. $\mathrm{f}$ : Labelled proteins in the control nerve as in e, except that the length of nerve between 39 and $60 \mathrm{~mm}$ from the ganglion was taken. Only the tubulin region of each gel is shown. Arrows point to the four extra spots found only in the transported material. The neurofilament triplet (Nf 68, Nf 160 and Nf 200) and actin (A) are also indicated. 

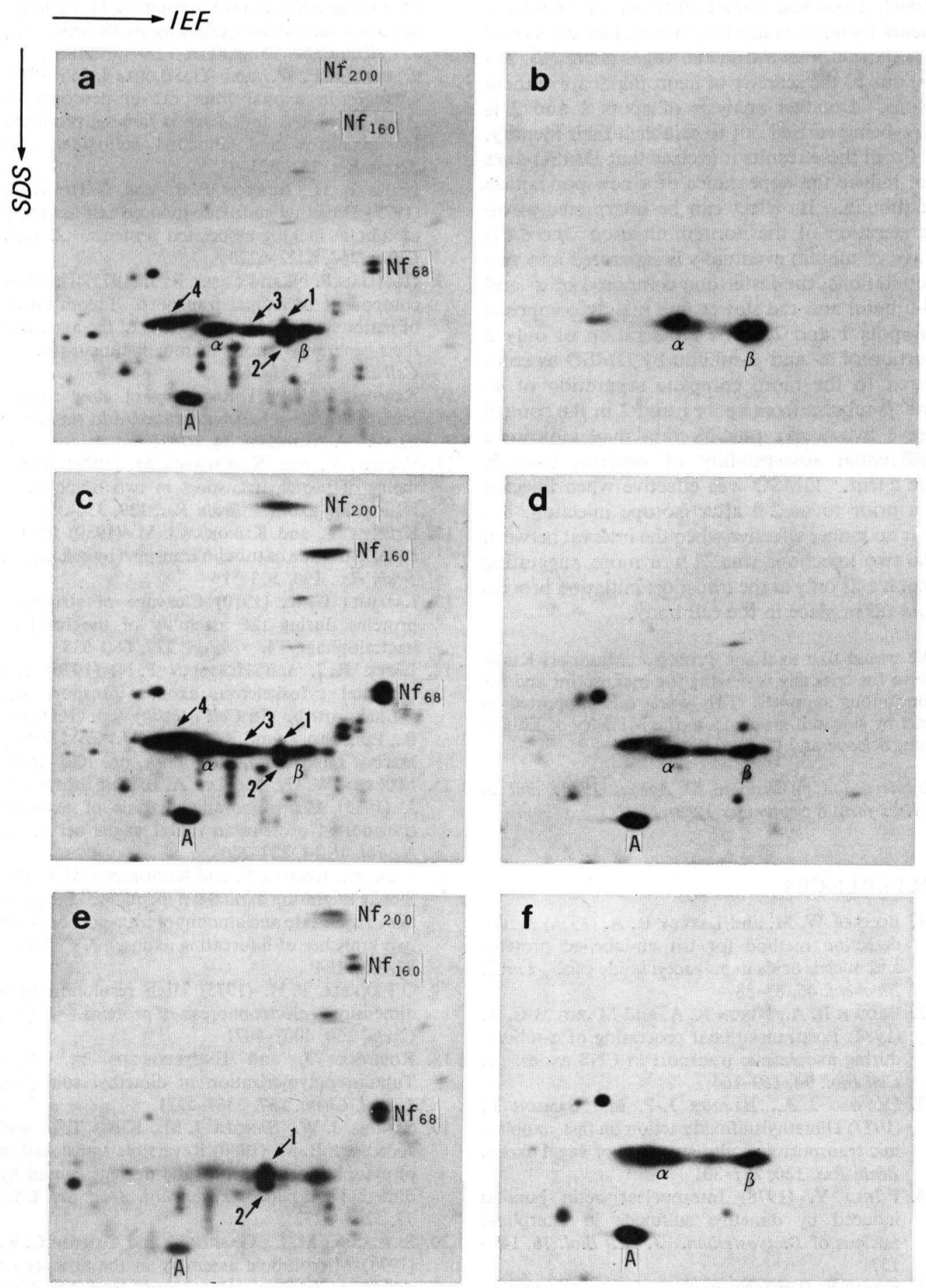

Fig. 2 
ments, since the triplet proteins of neurofilaments themselves are not detected in the slowly transported material in the vagal nerve $(15,21-$ 23) due to the scarcity of neurofilaments in these axons. Detailed analysis of spots 1 and 2 is now being carried out to establish their identity.

From these results it is clear that DMSO does not induce the appearance of a new population of tubulin. Its effect can be interpreted as an acceleration of the normal situation where the wave of tubulin eventually is separated into two populations, the faster one composed of $\alpha$ - and $\beta$-tubulin and the slower one mainly composed of spots 1 and 2 . The acceleration of only a portion of $\alpha$ - and $\beta$-tubulin by DMSO as compared to the more complete separation of $\alpha$ and $\beta$-tubulin from spots 1 and 2 in the control nerve two weeks postinjection may indicate a differential susceptibility of neurons towards the agent. DMSO was effective when injected $2 \mathrm{~h}$ prior to or $2 \mathrm{~h}$ after isotope injection, but was no longer effective when the interval between the two injections was $24 \mathrm{~h}$ or more, suggesting that it acts only at the transport initiation process that takes place in the cell body.

We would like to thank Professor Masanori Kurokawa for critically reviewing the manuscript and for continuous support. This work was supported in part by research grants from the Ministry of Education, Science and Culture, Japan.

Received for publication 10 August 1983; and in revised form 8 September 1983

\section{REFERENCES}

1. Bonner W. M. and Laskey R. A. (1974) A film detection method for tritium-labelled proteins and nucleic acids in polyacrylamide gels. Eur.J. Biochem. 46, 83-88

2. Brown B. A., Nixon R. A. and Marotta C. A. (1982) Posttranslational processing of $\alpha$-tubulin during axoplasmic transport in CNS axons. $J$. Cell Biol. 94, 159-164

3. Donoso J. A., Illanes J.-P. and Samson F. (1977) Dimethylsulfoxide action on fast axoplasmic transport and ultrastructure of vagal axons. Brain Res. 120, 287-301

4. FuKUI Y. (1978) Intranuclear actin bundles induced by dimethyl sulfoxide in interphase nucleus of Dictyostelium. J. Cell Biol. 76, 146157

5. FukUi Y. (1980) Formation of multinuclear cells induced by dimethyl sulfoxide: inhibition of cytokinesis and occurrence of novel nuclear division in Dictyostelium cells. J. Cell Biol. 86, 181-189

6. Fukui Y. and Katsumaru H. (1980) Dynamics of nuclear actin bundle formation by dimethyl sulfoxide and factors affecting its development. J. Cell Biol. 84, 131-140

7. Gamache F. W. and Gamache J. F. (1974) Changes in axonal transport in neurones of Asterias vulgaris and Asterias forbesei produced by colchicine and dimethyl sulfoxide. Cell Tissue Res. 152, 423-435

8. Himes R. H., Burton P. R. and Gaito J. M. (1977) Dimethyl sulfoxide-induced self-assembly of tubulin lacking associated proteins. J. Biol. Chem. 252, 6222-6228

9. Hoffman P. N. and LaseK R. J. (1975) The slow component of axonal transport. Identification of major structural polypeptides of the axon and their generality among mammalian neurons. $J$. Cell Biol. 66, 351-366

10. KomiYa Y. (1983) Recovery of slow axonal transport after colchicine treatment in rat sciatic nerve. J. Neurobiol. 14, 87-91

11. KomiYa Y. and Kurokawa M. (1978) Asymmetry of protein transport in two branches of bifurcating axons. Brain Res. 139, 354-358

12. KomiYa Y. and Kurokawa M. (1980) Preferential blockade of tubulin transport by colchicine. Brain Res. 190, 505-516

13. Laemmli U. K. (1970) Cleavage of structural proteins during the assembly of the head of bacteriophage T4. Nature 227, 680-685

14. LASEK R. J. and Hoffman P. N. (1976) The neuronal cytoskeleton, axonal transport and axonal growth. In Cell Motility (ed. Goldman R., Pollard T. and Rosenbaum J.) Cold Spring Harbor Laboratory, New York, pp. 1021-1049

15. McLean W. G., McKay A. L. and Suöstrand J. (1983) Electrophoretic analysis of axonally transported proteins in rabbit vagus nerve. $J$. Neurobiol. 14, 227-236

16. Mori H., KomiYa Y. and Kurokawa M. (1979) Slowly migrating axonal polypeptides. Inequalities in their rate and amount of transport between two branches of bifurcating axons. J. Cell Biol. 82, 174-184

17. O'Farrell P. H. (1975) High resolution twodimensional electrophoresis of proteins. J. Biol. Chem. 250, 4007-4021

18. Robinson J. and ENGelborghs Y. (1982) Tubulin polymerization in dimethyl sulfoxide. J. Biol. Chem. 257, 5367-5371

19. SANGer J. W., SANGer J. M., Kreis T. E. and JocKUSCH B. M. (1980) Reversible translocation of cytoplasmic actin into the nucleus caused by dimethyl sulfoxide. Proc. Natl. Acad. Sci. USA 77, 5268-5272

20. Shelanski M. L., Gaskin F. and Cantor C. R. (1973) Microtubule assembly in the absence of added nucleotides. Proc. Natl. Acad. Sci. USA 70, 765-768

21. Tashiro T., Kasai H. and Kurokawa M. (1980) A calmodulin-related polypeptide rapidly migrates within the mammalian nerve. Biomedical Res. 1, 292-299 
22. TASHIRo T. and KomiYa Y. (1983) Subunit composition specific to axonally transported tubulin. Neuroscience 9, 943-950

23. Yokoyama K., Tsukita S., Ishikawa H. and
Kurokawa M. (1980) Early changes in the neuronal cytoskeleton caused by $\beta, \beta^{\prime}$-iminodipropionitrile: Selective impairment of neurofilament polypeptides. Biomedical Res. 1, 537-547 